\title{
ANALISA PENGGUNAAN SILICON CONTROLLED RECTIFIER PADA ELEKTROPLATING TEMBAGA/BAJA KARBON RENDAH
}

\author{
Vicky Prasetia ${ }^{1}$, Roy Aries Permana $\mathrm{T}^{2}$ \\ 1,2Program Studi Teknik Listrik, Politeknik Negeri Cilacap \\ vickyprasetia@gmail.com ${ }^{1}$, igan102889@gmail.com ${ }^{2}$
}

\begin{abstract}
Abstrak
Kata Kunci:

Elektroplating;

Tembaga, Baja Karbon

Rendah;

Silicon Controlled

Rectifier.

Elektroplating merupakan salah satu rekayasa perbaikan karakteristik material logam. Pelapisan tembaga merupakan pelapisan pendahuluan sebelum dilakukan pelapisan selanjutnya untuk baja. Luas permukaan material seiring dengan kebutuhan kuat arus yang diperlukan pada proses pelapisan normal. Namun, arus yang terlalu besar mengalir ke katoda mengakibatkan pengikisan di anoda. Silicon Controlled Rectifier (SCR) adalah komponen yang terbuat dari bahan semiconductor silicon dan mempunyai fungsi sebagai pengendali ataupun switch. Silicon Controlled Rectifier dapat digunakan untuk menurunkan arus pelapisan pada elektroplating tembaga. Pengaturan arus pelapisan dapat dilakukan pada elektroplating tembaga terhadap katoda baja karbon rendah dengan luas penampang $7500 \mathrm{~mm}^{2}$ sebesar 4,5 A; $5 \mathrm{~A} ; 6 \mathrm{~A} ; 6,5 \mathrm{~A}$ dan 6,7 A. Hasil pelapisan tembaga terbaik dengan waktu pelapisan 10 menit ditunjukkan pada arus 6,5 A dengan massa pelapis sebesar 1,11 gram dan 1,06 gram. Hal ini membuktikan perlu adanya penurunan arus maksimal agar tercapainya pelapisan optimal.
\end{abstract}

\begin{tabular}{ll}
\hline & Abstract \\
\hline Keywords: & $\begin{array}{l}\text { Electroplating is one of the engineering improvements of the metal materials characteristics. } \\
\text { Electroplating; }\end{array}$ \\
Copper; & material is in line with the strong current requirements for the normal coating process. However, \\
Low Carbon Steel; & if there is a massive current flow into the cathode, it leads to erosion of the anode. Silicon \\
Silicon Controlled & Controlled Rectifier (SCR) is a component made of semiconductor silicon. It has a function as a \\
Rectifier. & controller or switch. Silicon Controlled Rectifiers can be used to reduce coating currents in \\
& copper electroplating. The setting of the coating current can be done on copper electroplating of \\
low carbon steel cathodes with a cross-sectional area of $7500 \mathrm{~mm}^{2}$ of $4.5 \mathrm{~A} ; 5 \mathrm{~A} ; 6 \mathrm{~A} ; 6.5 \mathrm{~A}$ and \\
6.7 A. The best copper coating results with a 10 minute coating time are shown in the current \\
6.5 A with a coating mass of 1.11 grams and 1.06 grams. This proves the need for a reduction in \\
the maximum current so that optimal coating is achieved.
\end{tabular}

\footnotetext{
Alamat korespondensi:

E-mail: diansheva@yahoo.co.id

ISSN : 2087-1627
} 


\section{Pendahuluan}

Setiap jenis material logam memiliki karakteristik keunggulan dan kelemahan. Daya guna logam dapat menurun karena banyak faktor, salah satunya disebabkan oleh proses produksi dan korosi. Teknologi pengerjaan logam, pelapisan, merupakan salah satu rekayasa perbaikan karakteristik material logam. Fungsi utama pelapisan, pengerjaan akhir (metal finishing), adalah memperbaiki penampilan, memperbaiki kehalusan/bentuk permukaan material dan memberikan sifat tahan korosi [1].

Pada umumnya proses pelapisan (electroplating) di industri logam menggunakan transformator yang output-nya disearahkan tanpa alat pengatur arus, sehingga mengakibatkan arus searah (DC) keluaran alat electroplating tetap. Penelitian Basmal (2011) menjelaskan bahwa luas permukaan material seiring dengan kebutuhan kuat arus yang diperlukan pada proses pelapisan normal. Namun, arus yang terlalu besar mengalir ke katoda mengakibatkan pengikisan di anoda [2]. Hasil pelapisan menjadi kurang maksimal dan menyebabkan cacat pada benda kerja yang berupa kerak hitam. Penelitian Didik (2012) menggunakan saklar rotari untuk mengatur tegangan input. Alat pelapisan logam dibuat dengan variasi tegangan 12 $\mathrm{V}, 18 \mathrm{~V}$, dan $25 \mathrm{~V}$. Penelitian tersebut menghasilkan data tegangan kerja optimal electroplating tembaga sebesar $12 \mathrm{~V}$ dengan arus maksimal 5A [3].

Komponen elektronik, silicon controlled rectifier (SCR), digunakan sebagai kontrol arus elektroplating tembaga sehingga dapat mengoptimalkan pelapisan logam tembaga pada baja karbon rendah. Alat pelapisan logam ini dirancang dengan output $12 \mathrm{~V} / 50 \mathrm{~A}$.

\section{Tinjauan Studi}

\subsection{Elektroplating}

Elektroplating adalah proses pelapisan logam yang menggunakan arus listrik DC melalui metode elektrolisa. Elektroplating memberikan suatu perlindungan logam dari korosi dengan memanfaatkan logam-logam tertentu sebagai pelindung misalnya tembaga, nikel, seng, krom, emas, perak, kuningan, perunggu dan lainnya. Pelapisan tembaga merupakan pelapisan pendahuluan sebelum dilakukan pelapisan selanjutnya untuk baja (dan paduannya). Pelapisan tembaga banyak digunakan dengan tujuan sebagai pelapis perantara serta meningkatkan daya hantar listrik dan panas dengan larutan tembaga sulfat atau tembaga sianida [4].

Pada sistem elektroplating, apabila sistem diberi tegangan ion-ion maka bergerak menuju elektroda. Arus listrik yang mengalir ke dalam larutan elektrolit mengakibatkan pergerakan dan pembebasan ion-ion. Hubungan antara jumlah arus listrik yang mengalir dengan jumlah zat yang dibebaskan di dalam larutan tersebut dinyatakan dalam Hukum Faraday, yaitu:

- Jumlah zat-zat yang terbentuk pada elektroda pada suatu sel sebanding dengan jumlah arus yang mengalir.

- Jumlah zat-zat yang dihasilkan oleh arus yang sama dalam sel yang berbeda adalah sebanding dengan berat ekuivalen masingmasing zat itu.

Hukum 1 membuktikan adanya hubungan antara reaksi kimia dan jumlah arus listrik yang mengalir. Menurut Faraday, arus 1 ampere mengalir selama 96.496 detik (26,8 jam) membebaskan 1,008 gram hidrogen $(\mathrm{H})$ dan 35,437 gram khlor (Cl) dari larutan asam khlorida. Hasil yang ditunjukkan bahwa 96.496 coulomb arus listrik membebaskan satu satuan berat ekivalen ion positif dan negatif $(1$ faraday $=96.500$ coulomb $)$. Untuk menentukan logam yang terdeposisi dengan arus dan waktu dapat ditentukan seperti persamaan (1).

$$
G=\frac{I \cdot t}{96500} \times \frac{A r / M r}{\text { valensi }}
$$

dengan:

$$
\begin{array}{ll}
\mathrm{G} & =\text { berat logam yang terdeposisi (gram) } \\
\mathrm{I} & =\text { rapat arus yang mengalir (ampere) } \\
\mathrm{t} & =\text { waktu pelapisan (detik) }
\end{array}
$$

$\mathrm{Ar} / \mathrm{Mr}=$ massa atom/molekul relatif

Skema elektroplating dapat dilihat pada gambar di bawah ini.

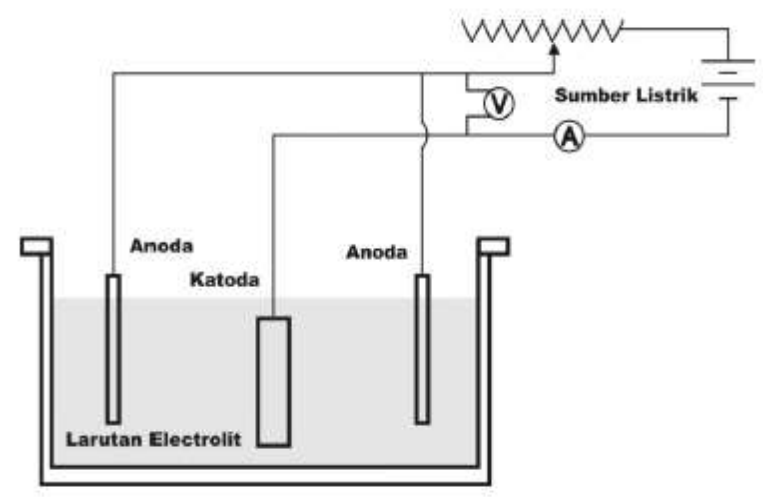

Gambar 1. Skema Elektroplating [3]

\subsection{Transformator}

Transformator atau yang sering disebut trafo adalah komponen elektrik yang dapat menghubungkan jaringan listrik yang mempunyai berbagai macam tegangan sehingga tenaga listrik dapat didistrubusikan secara meluas dan berfungsi untuk mengubah (menaikkan/menurunkan) tegangan listrik AC. Trafo terdiri atas inti besi, kumparan primer, dan kumparan sekunder. Pengertian transformator memiliki dua terminal yaitu, terminal input terdapat pada kumparan primer, dan terminal output terdapat pada kumparan sekunder. Secara umum trafo memiliki dua jenis 
yaitu step up untuk menaikkan tegangan dan step down untuk menurunkan tegangan. Jenis transformator yang lainnya adalah autotransformator, autotransformator variabel, transformator pulsa, transformator isolasi, dan transformator tiga fasa [4].

Langkah awal yang diambil dalam merancang transformator adalah penentuan kapasitas transformator meliputi tegangan dan arus. Persamaan 2 sampai persamaan 4 menunjukkan penentuan kapasitas transformator.

$$
\begin{aligned}
& P s=V \times I \\
& P p=\frac{P s}{\eta} \\
& I p=\frac{P p}{V p}
\end{aligned}
$$

Dengan $P s$ adalah daya sekunder (W), $P p$ adalah daya primer (W), $V s$ adalah tegangan sekunder (V), $V p$ adalah tegangan primer (V), Is adalah arus sekunder (A), Ip adalah arus primer (A) dan $\eta$ adalah efisiensi transformator. Dengan mengetahui nilai dari arus primer maupun sekunder, maka diameter kawat yang digunakan dapat ditentukan seperti yang ditunjukkan pada persamaan 5 dan persamaan 6 .

$$
\begin{aligned}
& \varnothing p=0,7 \sqrt{I p} \\
& \varnothing s=0,7 \sqrt{I s}
\end{aligned}
$$

Dengan $\varnothing_{p}$ adalah diameter kawat lilitan primer $(\mathrm{mm})$ dan $\emptyset_{s}$ adalah diameter kawat lilitan sekunder (mm).

Dimensi inti dapat ditentukan dengan rumus empiris yang terlihat pada persamaan 7 sampai persamaan 10 dapat dilihat pada gambar di bawah ini.

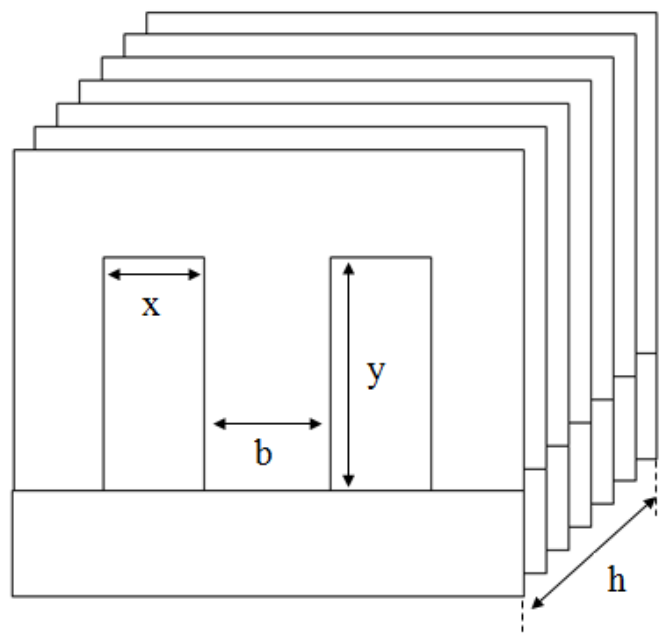

Gambar 2. Dimensi Transformator [5]

$$
\begin{aligned}
& A=b \times h \\
& b=\left(\frac{1,5 P p}{9,9}\right)^{\frac{1}{3}} \\
& h=\frac{b}{0,6561} \\
& m_{n}=1,5 \times P p \times 7,8
\end{aligned}
$$

Dengan $A$ adalah luas penampang efektif inti yang diberi lilitan koil $(\mathrm{cm} 2), b$ adalah sisi penampang melintang inti transformator transformator $(\mathrm{cm}), h$ adalah sisi penampang memanjang inti transformator $(\mathrm{cm})$, dan $m_{n}$ adalah massa inti transformator (gram).

Untuk menentukan jumlah lilitan masingmasing koil transformator, terlebih dahulu ditentukan faktor lilitan. Perhitungan faktor lilitan didapatkan dari perhitungan tegangan induksi seperti yang terlihat pada persamaan 11 .

$$
E=4,44 \cdot f \cdot B_{\max } \cdot A \cdot 10^{-8}
$$

Dengan melihat tipikal transformator yang memiliki data-data seperti yang tertera pada Tabel 1 dan frekuensi yang digunakan adalah $50 \mathrm{~Hz}$, maka faktor lilitan dapat dihitung menggunakan persamaan empiris seperti pada persamaan 12 dan persamaan 13.

Tabel 1. Karakteristik Transformator [6]

\begin{tabular}{|l|l|}
\hline \multicolumn{1}{|c|}{ Karekteristik } & \multicolumn{1}{c|}{ Nilai } \\
\hline Bmax & 9000 gauss/cm2 \\
\hline Rugi-rugi inti & $<1 \%$ Po \\
\hline Rugi-rugi total & $1-3 \%$ Po \\
\hline Efisiensi & $85-95 \%$ \\
\hline
\end{tabular}

$$
\begin{aligned}
& \frac{N}{E}=\frac{50}{A} \\
& \frac{N}{E}=\text { gulungan per volt (gpv) }
\end{aligned}
$$

Dari persamaan 12 dan persamaan 13 didapatkan besarnya gpv (gulungan per volt) sehingga jumlah lilitan primer maupun sekunder dapat ditentukan seperti yang tertera pada persamaan (14) dan persamaan 15.

$$
\begin{aligned}
& n_{s}=\mathrm{gpv} \times V_{s} \\
& n_{p}=1,1 \times \mathrm{gpv} \times V_{s}
\end{aligned}
$$

dengan $n p$ adalah jumlah lilitan primer (lilit) dan $n s$ adalah jumlah lilitan sekunder (lilit) [6].

\subsection{Silicon Controlled Rectifier}

Silicon Controlled Rectifier (SCR) adalah komponen yang terbuat dari bahan semiconductor 
silicon dan mempunyai fungsi sebagai pengendali ataupun switch. SCR juga sering disebut thyristor. Rangkaian dasar SCR dapat dilihat pada gambar di bawah ini.

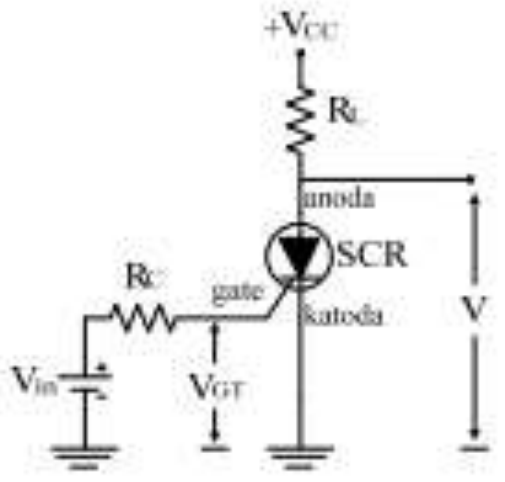

Gambar 3. Rangkaian dasar SCR

Tegangan input $\left(V_{\text {in }}\right)$ yang dibutuhkan untuk memicu (men-trigger) sebuah SCR sebesar

$$
V_{\text {in }}=V_{G T}+I_{G T} R
$$

Dimana $V_{G T}$ dan $I_{G T}$ adalah tegangan dan arus pemicu gate.

Setelah SCR dalam kondisi ON maka SCR akan tetap ON meskipun $V_{\text {in }}$ dikurangi menjadi nol. Satu-satunya cara untuk me-reset SCR adalah dengan mengurangi $V c c$ ke nilai yang lebih rendah. Karena arus holding (IH) mengalir melalui hambatan $(R L)$ sehingga tegangan catu $V c c$ untuk kondisi OFF harus lebih kecil dari :

$$
V_{c c}=0,7+I_{H} R_{L}
$$

Dimana IH adalah arus holding yang mempertahankan SCR agar tetap ON [6].

\section{Metode Penelitian}

\subsection{Pembuatan Transformator}

Melakukan perhitungan perancangan dan pembuatan transformator dengan output keluaran $12 \mathrm{~V} / 50 \mathrm{~A}$ atau $600 \mathrm{Watt}$ sesuai dengan persamaan 2 hingga persamaan 15 . Hasil dari perhitungan didapatkan perancangan transformator dapat dilihat pada Tabel 2.

Pada Pembuatan Rangkaian SCR, Rangkaian SCR terdiri dari Dioda Bridge dengan kapasitas 50A, SCR kapasitas 50 A daya 60 VDC, dan Potensiometer $1 \mathrm{kOhm}$ sebagai trigger sesuai dengan Gambar 3.
Tabel 2. Perhitungan Perancangan Trafo

\begin{tabular}{|l|l|}
\hline \multicolumn{1}{|c|}{ Keterangan } & \multicolumn{1}{c|}{ Nilai } \\
\hline Ps & $600 \mathrm{~W}$ \\
\hline Asumsi Efisiensi & 0,8 \\
\hline Pp & $750 \mathrm{~W}$ \\
\hline Ip & $3,409 \mathrm{~A}$ \\
\hline Diameter Kawat Primer & $\begin{array}{l}1,29 \mathrm{~mm} \text { dibulatkan } \\
\text { menjadi 1,5 mm }\end{array}$ \\
\hline $\begin{array}{l}\text { Diameter } \\
\text { Sekunder }\end{array}$ & $\begin{array}{l}\text { 4,94 mm dibulatkan } \\
\text { menjadi 5 mm }\end{array}$ \\
\hline Luas Penampang inti & $35,72 \mathrm{~mm} 2$ \\
\hline $\begin{array}{l}\text { Massa inti trafo yang } \\
\text { dibutuhkan }\end{array}$ & 8775 gram \\
\hline Gulungan per Volt & 1,4 gpv \\
\hline Jumlah Lilitan Primer & 308 lilitan \\
\hline Jumlah lilitan sekunder & $\begin{array}{l}18,48 \text { lilitan dibulatkan } \\
\text { menjadi 19 lilitan }\end{array}$ \\
\hline
\end{tabular}

\subsection{Elektroplating Tembaga}

Spesifikasi pengerjaan elektroplating tembaga sebagai berikut:

1) Larutan Elektrolit dan Anoda

Larutan elektrolit yang digunakan adalah Tembaga Sianida 100 gr/liter yang dicampur dengan Sodium Sianida 25 gr/liter sejumlah 30 liter. Anoda yang digunakan adalah anoda tembaga dengan panjang $40 \times 8 \times 1 \mathrm{~cm}$ dengan massa $2,5 \mathrm{~kg}$ sebanyak 2 buah.

2) Bak plating

Bak plating berbahan plastik dengan dimensi $50 \times 30 \times 30 \mathrm{~cm}$ dengan jarak anoda ke katoda masing-masing $15 \mathrm{~cm}$.

3) Katoda

Katoda yang digunakan adalah baja karbon rendah dengan dimensi $100 \times 75$ × 3 mm yang telah digerinda dan diamplas dengan menggunakan amplas 1000 mesh sebanyak 12 buah.

4) Proses Pelapisan

Dilakukan pelapisan baja karbon rendah dengan anoda tembaga dengan waktu pelapisan tiap-tiap spesimen selama 10 menit.

\subsection{Teknik Pengumpulan Data}

Teknik pengumpulan data yang digunakan dalam penelitian ini adalah teknik eksperimen, yaitu mengumpulkan data dengan cara menguji atau mengukur objek yang diuji selanjutnya mencatat data-data yang diperlukan. Adapun beberapa parameter yang diuji untuk dicatat hasil pengujiannya antara lain adalah arus yang mengalir dan massa pelapis tembaga yang menempel.

\section{Hasil dan Pembahasan}

Pada penelitian ini dihasilkan alat elektroplating tembaga dengan SCR. alat ini dapat digunakan untuk elektroplating tembaga dengan katoda baja karbon rendah. Tegangan keluaran alat ini sebesar 11,78 V dan arus maksimal sebesar $44 \mathrm{~A}$ 
Tabel 3. Hasil Pengujian SCR pada Elektroplating Tembaga

\begin{tabular}{|c|c|c|c|c|c|c|c|c|}
\hline Tegangan & Arus & Rapat Arus & \multicolumn{2}{|c|}{ Massa Awal (gr) } & \multicolumn{2}{c|}{ Massa Akhir (gr) } & \multicolumn{2}{c|}{ Massa Pelapis (gr) } \\
\cline { 4 - 9 } V & $\mathbf{A}$ & A/dm $^{2}$ & $\mathbf{1}$ & $\mathbf{2}$ & $\mathbf{1}$ & $\mathbf{2}$ & $\mathbf{1}$ & $\mathbf{2}$ \\
\hline & 6.7 & 8.93 & 313.13 & 312.92 & 314.24 & 313.98 & 1.11 & 1.06 \\
& 6.5 & 8.67 & 314.24 & 316.21 & 315.45 & 317.39 & 1.21 & 1.18 \\
8.8 & 6 & 8.00 & 310.76 & 312.04 & 311.64 & 312.9 & 0.88 & 0.86 \\
& 5 & 6.67 & 309.88 & 308.75 & 310.58 & 309.44 & 0.7 & 0.69 \\
& 4.5 & 6.00 & 308.43 & 308.81 & 309.04 & 309.37 & 0.61 & 0.56 \\
& 4 & 0.00 & 311.23 & 313.42 & 311.23 & 313.42 & 0 & 0 \\
\hline
\end{tabular}

Tabel 4. Hasil Perhitungan Massa Pelapisan antara Pengujian dan Hukum Faraday

\begin{tabular}{|c|c|c|c|c|c|c|c|}
\hline \multirow{2}{*}{$\begin{array}{c}\text { Tegangan } \\
\mathrm{V}\end{array}$} & \multirow{2}{*}{$\begin{array}{c}\text { Arus } \\
\text { A }\end{array}$} & \multirow{2}{*}{$\begin{array}{c}\text { Rapat Arus } \\
\mathrm{A} / \mathrm{dm}^{2}\end{array}$} & \multicolumn{2}{|c|}{ Massa Pelapis (gr) } & \multirow{2}{*}{$\mathbf{G}$} & \multicolumn{2}{|c|}{ e } \\
\hline & & & 1 & 2 & & 1 & 2 \\
\hline \multirow{6}{*}{8.8} & 6.7 & 8.93 & 1.11 & 1.06 & 1.32 & 0.16 & 0.20 \\
\hline & 6.5 & 8.67 & 1.21 & 1.18 & 1.28 & 0.06 & 0.08 \\
\hline & 6 & 8.00 & 0.88 & 0.86 & 1.19 & 0.26 & 0.27 \\
\hline & 5 & 6.67 & 0.7 & 0.69 & 0.99 & 0.29 & 0.30 \\
\hline & 4.5 & 6.00 & 0.61 & 0.56 & 0.89 & 0.31 & 0.37 \\
\hline & 4 & 0.00 & 0 & 0 & 0.79 & 1.00 & 1.00 \\
\hline
\end{tabular}

saat dialirkan pada beban 2,3 Ohm. Penyimpangan kapasitas kerja alat dengan perancangan sebesar $13,61 \%$. Hasil pengujian elektroplating tembaga menghasilkan data pada Tabel 3 dan Tabel 4.

Hasil pengujian pada tabel di atas menjelaskan arus maksimal elektroplating tembaga dengan katoda baja karbon rendah sebesar 6,7 ampere dengan rapat arus $8,93 \mathrm{~A} / \mathrm{dm}^{2}$. Hasil pengujian juga menjelaskan bahwa SCR mampu menurunkan arus pelapisan dari 6,7 A; 6,5 A; 6 A; 5 A; 4,5 A hingga mencapai titik minimal 4 ampere. Hal ini dibuktikan pada pengaturan arus menuju 4 ampere, tidak ada arus dan unsur tembaga yang menempel pada baja karbon rendah. Hal ini terjadi karena pengaruh SCR, dimana besarnya tegangan pelapisan tidak lebih besar dari Vcc pada rangkaian tersebut.

Hasil dari pelapisan baja karbon rendah dengan tembaga selama 10 menit dapat dilihat pada Gambar 4. Hasil pelapisan tembaga terbaik dengan waktu pelapisan 10 menit ditunjukkan pada arus 6,5 A menghasilkan massa pelapis sebesar 1,11 gram dan 1,06 gram. Grafik tersebut menunjukkan massa pelapis terbanyak tidak berada pada arus maksimal pelapisan. Hal ini membuktikan bahwa arus yang terlalu besar mengakibatkan pengikisan ion pada anoda terlalu besar dan membentuk gelembung banyak gelembung yang dapat menghambat proses pelapisan. Arus pelapisan yang terlalu besar juga mengakibatkan kerak hitam pada katoda. Hasil pelapisan dengan arus maksimal dan setelah arus diturunkan menggunakan SCR dapat dilihat pada Gambar 5.

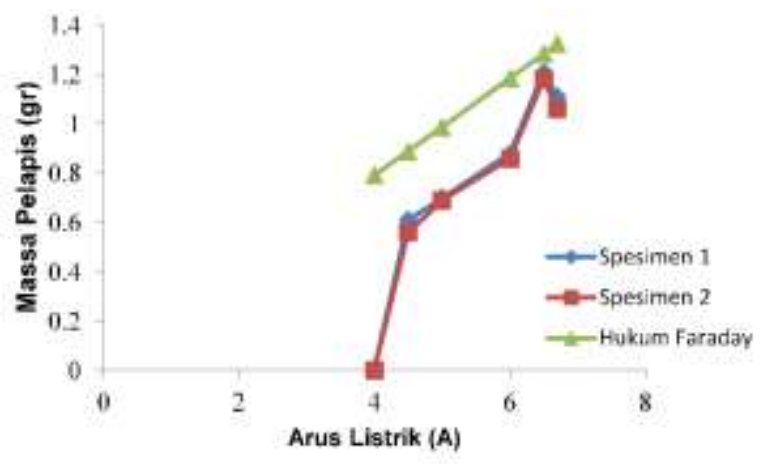

Gambar 4. Grafik Hasil Pelapisan

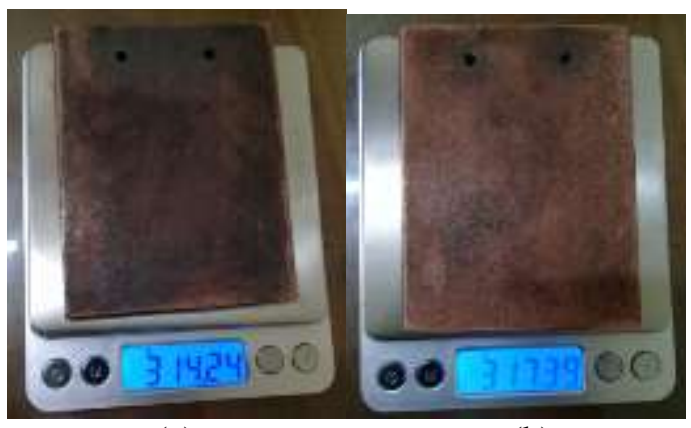

(a)

(b)

Gambar 5. Hasil pelapisan dengan (a) arus maksimal dan (b) setelah arus diturunkan menggunakan SCR

\section{Kesimpulan}

Silicon Controlled Rectifier dapat digunakan untuk menurunkan arus pelapisan pada elektroplating tembaga. Pengaturan arus pelapisan dapat dilakukan pada elektroplating tembaga 
terhadap katoda baja karbon rendah dengan luas penampang $7500 \mathrm{~mm}^{2}$ sebesar 4,5 A; $5 \mathrm{~A} ; 6 \mathrm{~A}$; 6,5A dan 6,7 A. Hasil pelapisan tembaga terbaik dengan waktu pelapisan 10 menit ditunjukkan pada arus 6,5 A menghasilkan massa pelapis sebesar 1,11 gram dan 1,06 gram. Hal ini membuktikan perlu adanya penurunan arus maksimal agar tercapainya pelapisan optimal.

\section{Daftar Pustaka}

[1] A. ROZAK, "Analisis Kepadatan Pada Proses Pelapisan Nikel Dengan Variasi Tegangan Dan Lama Pencelupan Baja ST 41," J. Tek. Mesin, vol. 5, no. 01, 2017.

[2] Basmal, "Pengaruh Rapat Arus Dan Waktu Pelapisan Pada Proses Electroplating Terhadap Ketebalan Lapisan Krom | Politeknosains," POLITEKNOSAINS J. Ilm. lintas Teknol., vol. 10, no. 2, 2011.

[3] B. Suhendro, T. L. DS, and Suyamto, "Rancang Bangun Dan Analisis Alat
Pelapisan Tembaga Menggunakan Teknik Elektroplating," in SEMINAR NASIONAL SDM TEKNOLOGI NUKLIR VII, 2011.

[4] I. M. Sudana, I. A. A. Arsani, and I. G. . S. Waisnawa, "Alat Simulasi Pelapisan Logam Dengan Metode Elektroplating," Log. J. Ranc. Bangun dan Teknol., vol. 14, no. 3, p. 190, Mar. 2017.

[5] U. Margono, "Rancang Bangun Transformator 7,2 V/200 A sebagai Catu Daya Filamen Tabung TRIODA ITK 15-2 pada Generator COCKCROFT WALTON MBE LATEKS 300keV/20 mA." PTAPB-BATAN, Yogyakarta, 2012.

[6] D. Krisnandi, "Aplikasi Kontrol Switch Menggunakan Silicon Controlled Rectifier (SCR) Melalui Parallel Port," INKOM J. Informatics, Control Syst. Comput., vol. 1, no. 1, pp. 28-34, 2007. 